\title{
Ophthalmic diagnosis and medication use: How much do patients know?
}

\author{
Samuel Kyei ${ }^{1 *}$, Yaw Asamoah ${ }^{2}$, Felix Amoah ${ }^{1}$, Stephen Ocansey ${ }^{2,3}$ and Samuel Bert Boadi-Kusi ${ }^{1}$ \\ ${ }^{1}$ Department of Optometry, School of Allied Health Sciences, University of Cape Coast, Cape Coast, Ghana \\ ${ }^{2}$ Department of Geography and Regional Planning, Faculty of Social Sciences, University of Cape Coast, Cape Coast, Ghana \\ ${ }^{3}$ Department of Vision and Hearing Sciences, Faculty of Science and Technology, Anglia Ruskin University, Cambridge, UK
}

\begin{abstract}
Purpose: Review patients in hospitals of Ghana mostly do not have adequate knowledge of their diagnosis or have insufficient information about their medications. This study therefore aimed at assessing Ghanaian Ophthalmic Patients' knowledge of their ocular diagnosis and prescribed medications at their point of discharge.

Method: The study was a hospital-based cross-sectional survey involving 420 Review Ophthalmic Patients from four major teaching hospitals in Ghana. A semistructured questionnaire was used to collect data on their demographics, knowledge of their ocular conditions, prescribed medications and source of their knowledge.

Results: Out of the 420 participants, 219 (52.1\%) could name their diagnosis correctly whilst the remaining 201 (47.9\%) were unaware of their diagnosis. Majority $(60.0 \%)$ did not know the names of their prescribed medications. Up to $85.0 \%$ of the total respondents did not know any possible adverse effect of their medication.
\end{abstract} One's level of formal education and age enhanced their knowledge of medications and its possible side effects $(\mathrm{p}=0.000)$.

Conclusion: There was a general lack of knowledge among Ghanaian Ophthalmic patients regarding their diagnosis, names and adverse effects of medications.

\section{Introduction}

Patient education seen as an integral part of contemporary healthcare has two components- Clinical Patient Education (CPE) and Health Education. Clinical education is patient focussed and happens in a clinical setting. It encompasses the communication between healthcare providers and their patients and/or the patients' family regarding the patient's evaluation, diagnoses, prognosis, and specific needs associated with recommended interventions [1]. Health education on the other hand centres on wellness, prevention and health promotion [1].

It is widely acknowledged that patients acquire information on their disease condition and medical therapy from several sources which ultimately impact their knowledge. Nevertheless, there are concerns about the clarity, reliability and difficulty in understanding information sourced. Findings from our previous study among Ophthalmic Patients in Ghana indicated that Patient Information Leaflets (PILs) is beset with readability and comprehensibility issues rendering them less effective as an educational material except among the highly educated [2]. However in Ghana, total adult literacy rate is about $71.1 \%$, but secondary school participation is less than $50 \%$ of the population [3].

In the wake of these challenges associated with written information among less educated individuals, the use of medical jargons and layout setback in some PILs which may affect the retrieval of relevant information especially among ophthalmic patients, most of whom suffer from visual impairment; CPE remains the obvious conduit of informing patients [4].

In Ghana as in many developing nations, it is not uncommon to come across patients with history of eye disease management but are unaware of their diagnosis and the treatment given. It has been reported that lack of communication between health care providers and patients results in non-adherence which accounts for up to $55 \%$ of all abuses of prescribed drugs [5,6]. Educating the patients about their health status and medication use improve their knowledge about their condition, reduce anxiety and achieve increase participation in their therapy to enhance prognosis $[7,8]$.

Successful patient education and/or counselling can be evaluated by measurable outcomes, such as: knowledge, changes in attitudes and behaviour and adherence to medical therapy. However, the most widespread approach to evaluate patient education is to assess the patients' knowledge and understanding of their medical therapy [9].

This study was therefore designed to assess the knowledge of Review Ophthalmic Patients on their ocular diagnosis, treatment plan (names and purpose of their medications), contraindications and common side effects of their prescribed medications at the point of discharge in selected eye care facilities.

Correspondence to: Samuel Kyei, Department of Optometry, School of Allied Health Sciences, University of Cape-Coast, Cape-Coast, Ghana, Tel: +233 243309718, E-mail: skyei@ucc.edu.gh

Key words: prognosis, health promotion, illiteracy, contraindications, side effects

Received: November 24, 2015; Accepted: December 11, 2015; Published: December 15, 2015 


\section{Materials and methods}

\section{Study population}

The study population was ophthalmic patients reporting to the four teaching hospitals in the Ghana. These teaching Hospitals included the Korle-Bu Teaching Hospital (KBTH), Cape Coast Teaching Hospital (CCTH), KomfoAnokye Teaching Hospital (KATH), and Tamale Teaching Hospital (TTH). Ghana has ten administrative regions Ghana, but is usually subdivided into two demographic sectors, namely the Northern and Southern sectors. Two of the selected hospitals (Tamale Teaching Hospital and KomfoAnokye Teaching Hospital) cater for the northern sector whiles the other two (Cape Coast Teaching Hospital and Korle-Bu Teaching Hospital) serve the southern sector. In addition these selected hospitals are homogenous in the services they provide and have the full complement of eye care staff with the requisite logistics for the provision of comprehensive eye care.

\section{Sample size determination and subject selection}

The minimum sample size for the study was obtained by the formula $\mathrm{n}=\left[(1.96)^{2} \mathrm{P}(100-\mathrm{P})\right] / \mathrm{d}^{2}$. Where,

- $\mathrm{P}=$ proportion of the population in percentage

- $\mathrm{d}=$ degree of sampling error

Assuming that half of the patients (based on previous annual records of attendance Korle-Bu Teaching Hospital [KBTH]; 29800, Komfo Anokye Teaching Hospital [KATH]; 26553; Cape Coast Teaching Hospital [CCTH]; 5803, Tamale Teaching Hospital [TTH]; 8055: totalling 70211) who came to the various eye clinics would be available for the study, taking a confidence level of $95 \%$ and a sampling error of $5 \%$, the minimum sample size was computed as 384 . However, the sample size was adjusted to 420 to make for attrition rate.

A proportionate sampling was then used to determine the number for each facility using records of average annual attendance to each of these facilities (KBTH; 170, KATH 160; CCTH; 40; TTH; 50). Then, at the registry or records department, the allocated number of patients to each facility was randomly selected by lottery system. Participants were informed about the rationale of the study in the waiting area after balloting was done. The selection was done before patient-doctor consultation but the questionnaires were completed at discharge. This was done until the expected number for each facility was obtained. This process span for a maximum period of two weeks in each selected facility.

\section{Study design}

The study was a hospital-based cross sectional survey involving Review Ophthalmic Patients. Data was collected using a semi structured questionnaire which was in two parts. The first part (Section A) focussed on patients' demographics such as age, gender, educational status, occupation, marital status and others. The second part (Section B) asked questions regarding patients' knowledge of their diagnoses, common side effects, contraindications, precautions on their medication use at their point of discharge. A translated version of the questionnaire (in the local dialects) was used in situations where the patients could not read or write English. Who illiterate in both English and local had the translated version of the questionnaire read out to them for their response.

\section{Inclusion criteria}

All review patients aged 18 years or older (who were prescribed with ophthalmic medication) or any other medications for the purpose of managing their ocular ailment.

\section{Ethical consideration}

Ethical approval for the study was acquired from the Department of Optometry Ethics Review Committee of the University of Cape Coast (Ref No. FYP/15/005) and the research was performed in accordance with Helsinki Declaration on Research Regarding Human Subjects. A detailed rationale for the study was explained to respondents, after which respondents who agreed to participate signed a consent form. Confidentiality was ensured, and those who had inadequate knowledge were educated on their ocular disorder and medication use.

\section{Results}

\section{Demographic characteristics}

A total of 420 respondent participated in the study of which 204 (48.6\%) were males and $216(51.4 \%)$ were females. The mean age was 38.69 with standard deviation (SD) of \pm 18.891 . Almost half $(49.3 \%)$ of the participants were youth (18-35 years), $31.0 \%$ were adults (3659 years) and the aged group (60+) were $19.8 \%$. One hundred and twenty seven, (30.2\%) had formal education up to secondary level, vocational or technical training. Another $110(26.2 \%)$ had tertiary or post-secondary education, whilst $100(23.8 \%)$ of the respondents had basic education. Eighty three, (19.8\%) who had no formal education. Among the gender, 35 (17.2\%) of the male respondents had no formal education whilst $48(22.2 \%)$ of the female respondents had no formal education. Also, $61(29.9 \%)$ of the males had tertiary education whilst $49(22.7 \%)$ of the females had tertiary education. There was no statistical difference between the education levels of the male and female respondents $\left(\mathrm{x}^{2}=4.377, \mathrm{p}=0.224\right)$.

Out of the 420 participants, $32.1 \%$ were students. Some $17.6 \%$ were unskilled labourers, $15.2 \%$ were skilled labourers, $13.8 \%$ had no employment, $11.7 \%$ were self-employed, $8.1 \%$ retired workers, and $1.4 \%$ were occupied by clerical duties.

\section{Clinical patient education}

Two hundred and forty one (57.4\%) of the 420 reported they were given some education or information about their prescribed medication by healthcare provider while $179(42.6 \%)$ said they were not given any education or information at all. Out of the 241 who reported they had been educated on the use of their medications, 149 (61.8\%) received it from the doctor they consulted, 39 (16.2\%) from the pharmacist at the dispensary, $40(16.6 \%)$ indicated they were educated by both the doctor and pharmacist and $13(5.4 \%)$ by other health care providers (mainly nurses). The majority $(181,75.1 \%)$ of respondents who received any education, reported it was solely verbal education, while $19(7.9 \%)$ were educated by written means only, and 41 (17.0\%) were educated by both verbal and written means.

Majority (223 out of $241,92.5 \%$ ) of the respondents who were given drug instructions reported that the information given was clear and understandable. However, it was solely on dosage of their medication as reported by (127 out of the 241), 52.7\% of the respondents, $17 \%$ (41 of 241) said the education was on safety precautions of drug application, $7.1 \%$ (17 of 241) also said it was on medication handling and storage, $2.1 \%$ (5 of 241) on side effects and contraindications of drugs, $1.7 \%$ (4 of 241) on mechanism of drug action. Only $17 \%$ (41 of 241) reported receiving multiples information of dosage, safety precaution, medication handling and storage. Six (2.4\%) were not clear 
what information they had received.

\section{Evaluation $f$ patients' knowledge}

The study found that 219 of the 420 (52.1\%) respondents could name their diagnosis correctly whilst the remaining 201 (47.9\%) could not. About a third $(\mathrm{n}=143,34.0 \%)$ of the respondents knew the names of all their medications, a few $(n=25,6.0 \%)$ knew the names of some of their medications, and the majority $(n=252,60.0 \%)$ did not know the names of their medications. About a quarter $(n=63,15.0 \%)$ of the respondents knew at least one major adverse effect of their medication, with the majority $(n=357,85.0 \%)$ of the total respondents unaware of any adverse effect associated with the use of their medication/s. The ocular diseases/disorders named included glaucoma or ocular hypertension, allergy or dry eyes, cataract, eyelid diseases and infectious conjunctivitis (Figure 1).

The major classes of medications given to the respondents were anti-glaucoma, artificial tears, antibiotics, anti-allergic agents and nonsteroidal anti-inflammatory drugs. Most of the participants (222 out of $420,52.9 \%)$ were using one drug for their disease/disorder. Others 144 (34.3\%) were using two, 38 (9.0\%) were using three, 15 (3.6\%) were using four and only $1(0.2 \%)$ was using five different ophthalmic medications.

\section{Factors influencing patients knowledge}

The less the number of prescribed medicine to a patient the better their knowledge of their medication name $\left(\mathrm{x}^{2}=47.401, \mathrm{p}<0.001\right)$. Patients' knowledge of the name of the prescribed medication declined with polypharmacy from $44.2 \%$ among single drug users to $28.5 \%$ among those using two medications, $15.8 \%$ among those using 3 medications, and $6.7 \%$ (6.6 fold decline) among those using more than 3 different medications. However, there was no significant $(p=0.87)$ association between number of medication used and the respondents' knowledge of their diagnosis.

Some $55.9 \%$ (114 of 204) of the male respondents knew their diagnoses while less than half, $48.6 \%$ ( 105 of 216 ) the female respondents knew their diagnoses. Pearson's chi square test for association revealed no significant $\left(\mathrm{x}^{2}=2.223, \mathrm{p}=0.136, \mathrm{df}=1\right)$ association between the gender and the respondents' knowledge of their diagnoses. Similarly, there was no significant $(p=0.662)$ association between gender and the participants' knowledge of the common side effects of their medications but males had better $(\mathrm{p}=0.02)$ knowledge of medication name.

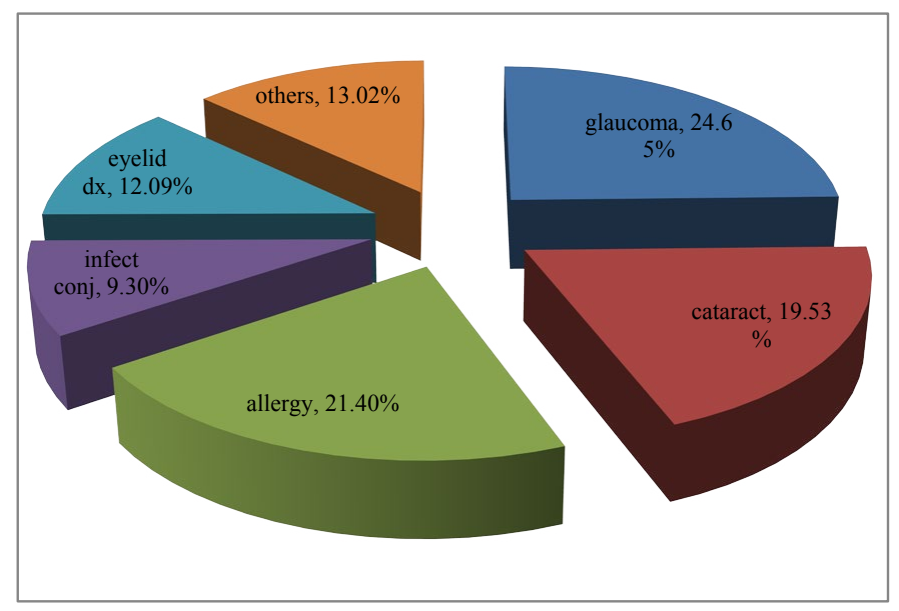

Figure 1. Distribution of respondents' conditions.
Table 1. Education level and knowledge of respondents' diagnoses.

\begin{tabular}{|l|c|c|c|}
\hline & \multicolumn{4}{|c|}{ Frequency (percentage \%) of respondents with knowledge } \\
of condition
\end{tabular}

$\left(x^{2}=14.367, p=0.02, d f=3\right)$

It was evident from the study that respondents knowledge of their diagnoses improved with advancing age as $47.3 \%$ of the youth (18-35 years) knew of their diagnosis, (49.2\%) among the adults (3659 years) and $(68.7 \%)$ of the aged (60+ years) had knowledge of their diagnosis. Advancing age was significantly $(\mathrm{p}=0.003)$ associated with one's knowledge of his/her diagnoses. Again the aged were more likely to know common side effects of their medication than the other age groups $(p=0.008)$ but not the name of their medication $(p=0.310)$. There was a significant association between the education level and the knowledge of conditions of the respondents. Respondents' knowledge of their diagnoses increased with increasing level of education (Table $1)$.

Only $10.0 \%$ ( 9 of 83 ) of the respondents with no formal education knew the names of all their medications as against $50.9 \%$ (56 of 110) of the respondents with tertiary education. Higher educational level was found to be associated ( $p=0.000)$ with one's ability to recall the name of his/her medication.

The unemployed had the least knowledge of their disorder ( 25 of $58,43.1 \%$ ) followed by the unskilled labourers ( 32 of $74,43.2 \%$ ), then students ( 62 of $135,45.9 \%$ ). Those who were self-employed $49.0 \%$ ( 24 of 49) knew about their diagnoses. Four out of the six, $(66.7 \%)$, who were engaged by clerical duties, $71.9 \%$, (46 of 64,) of skilled labourers, and $75.5 \%$, (26 of 34) retirees knew their diagnoses. One's occupation was found to be associated $(p=0.000)$ with knowledge of their diagnosis. In a multiple logistic regression analysis, respondent's level of education was the predictive factor of one's knowledge of his/her drug name. Respondents with basic education, secondary or tertiary education are 3.5, 6.7, 9.3 more likely to know the name of their drug compared to those with no formal of education (Table 2).

Multiple logistic regression analysis further indicated that an individual's age was predictive of his/her knowledge of common side effects of their prescribed medication. The aged are 1.2 more likely to know about the common side effects of their drug compared to the youths whiles the unemployed and uneducated females in their youthful stage are 0.1 less likely to know the names of their medications (Table 3).

\section{Discussion}

Although some studies have assessed patients' knowledge of their prescribed medications, non has been conducted among ophthalmic patients despite its acknowledged importance in the overall care process [10]. The higher proportion of females than males in this study could reflect the general demographics in Ghana or due the health consciousness of females compared to their male counterparts $[11,12]$. 
Table 2. Respondents' demographics and knowledge of drug name.

\begin{tabular}{|l|c|c|c|c|}
\hline Demographics & Odds ratio & S.E & P-value & $\mathbf{9 5 \%}$ CI \\
\hline Age group & & & & \\
Youth & 1.00 & - & - & \\
Adult & 1.391 & 0.461 & 0.319 & $0.727-2.664$ \\
Aged & 1.233 & 0.507 & 0.611 & $0.551-2.761$ \\
\hline Gender & & & & \\
Female & 1.00 & - & - & \\
Male & 1.207 & 0.266 & 0.393 & $0.784-1.859$ \\
\hline Education level & & & & \\
No formal education & 1.00 & - & - & \\
Basic education & 3.461 & 1.491 & 0.004 & $1.487-8.052$ \\
Secondary & 6.665 & 2.865 & 0.000 & $2.870-15.476$ \\
Tertiary & 9.272 & 4.202 & 0.000 & $3.815-22.537$ \\
\hline Occupation & & & & \\
Unemployed & 1.00 & - & - & \\
Student & 1.117 & 0.468 & 0.792 & $0.491-2.538$ \\
Retired & 1.874 & 0.972 & 0.226 & $0.678-5.181$ \\
Unskilled & 0.735 & 0.326 & 0.487 & $0.308-1.753$ \\
Skilled & 1.648 & 0.753 & 0.274 & $0.673-4.037$ \\
Self-employed & 0.445 & 0.229 & 0.115 & $0.163-1.218$ \\
\hline
\end{tabular}

Key: $\mathrm{SE}=$ Standard error

$\mathrm{CI}=$ Confidence Interval

Table 3.Respondents' demographics and knowledge of some adverse effects.

\begin{tabular}{|l|c|c|c|c|}
\hline Demographics & Odds ratio & S.E & P-value & $95 \%$ CI \\
\hline Age group & & & & \\
Youth & 1.00 & - & - & \\
Adult & 0.410 & 0.181 & 0.043 & $0.173-0.974$ \\
Aged & 1.215 & 0.451 & 0.601 & $0.586-2.516$ \\
\hline Gender & & & & \\
Female & 1.00 & - & - & \\
Male & 0.860 & 0.241 & 0.591 & $0.497-1.488$ \\
\hline Educational level & & & & \\
No formal education & 1.00 & - & - & \\
Basic education & 1.336 & 0.640 & 0.546 & $0.522-3.419$ \\
Secondary & 1.876 & 0.829 & 0.154 & $0.789-4.460$ \\
Tertiary & 1.757 & 0.780 & 0.216 & $0.720-4.287$ \\
\hline Occupation & & & & \\
Unemployed & 1.00 & - & - & \\
Employed & 1.042 & 0.329 & 0.896 & $0.561-1.935$ \\
\hline
\end{tabular}

Key:SE $=$ Standard error

$\mathbf{C I}=$ Confidence Interval

Other studies have found a higher prevalence of eye diseases among females than males, though this study found no such correlation [1316]. Studies have shown that patients are generally discontent with the clinical education given by health care providers even in cases where providers are convinced they have provided adequate information to their patients [17]. In this study, it was observed that most patient were educated on only some aspects of their medical therapy such as dosage, side effects, contraindication etc which reflected in the low knowledge of medication and disease condition among the respondents. A reason that could account for this is the low health care provider to patient ratio as practitioners tend to be the primary providers of Clinical Patient Education [18,19]. It obvious practitioners tend to be the primary providers of patient information [20]. Patients lack of knowledge on their diagnosis and medication implies poor informed consent which is more often than not deemed only important in cases where the procedure is insidious.

It could due to pressure from having to attend to the large number of cases at a time. In the most ideal scenario patients are required to be informed of all medications with probable side effects, as well as before the commencement of diagnostic investigations that may lead to additional testing and/or invasive procedures [21-23].

Authorities in health care advice a change in patient-physician relationships from a dictatorial trend to a more shared communication [24-26]. It is the ideal way to reduce patient penchants and to enhance their comprehension of the risks and benefits of investigative and remedial options to address their fears [26]. Other studies have studied predictors of medication knowledge among chronic diseases including diabetes and found it to be associated with education level among other [27]. Here, the most important predictive factors of ophthalmic patients' knowledge of their diagnoses and medical therapy were found to be age and educational level. Senility is associated with physiological and degenerative changes in the eye. The aged are therefore more affected by chronic eye diseases which require prolong management and frequent visits to the eye clinic, and as results have more information about their condition and medications than the other age groups. Higher education on the other hand is usually associated with the ability to read and comprehend sophisticated information. Since most PILs and patient educational materials are written in English, it was not unusual that educational level was strong predictor of patient's knowledge [10].

From the finding of this investigation, it can be concluded that Ophthalmic Patients' knowledge of their medication at the point of their discharge in Ghana was inadequate. More effort should be made to design patient tailored education which will inform them about their condition and medication use.

\section{Acknowledgement}

The author's are grateful to Dr Agnes Awuah for her support in typesetting this manuscript.

\section{Author's contribution}

SK conceived the idea, SK and YA designed the study. FA, SK, SO managed the acquisition of data, or analysis and interpretation of data. SB, FA, SK YA drafted the article. SB, SO, SK, YA revised it critically for important intellectual content, SK, YA, FA, SO, SB approved of the final version submitted.

\section{References}

1. Jones B (2000) Significance of patient education for health care and rehabilitation, in: Jones B, Basic concepts of patient education. Jones and Bartlett Publishers, Massachusetts, 2000, pp. 4-6.

2. Kyei S, Ocansey S, Koffuor GA, Abokyi S, Adu FK (2014) Patients' Information Leaflets: Its' Influence on Ophthalmic Patient Education and Medication Compliance. British Journal of Medicine and Medical Research 4: 4-7.

3. UNICEF (2013), At a glance: Ghana, Available at http://www.unicef.org/infobycountry/ ghana_statistics.html, Accessed on 3rd August, 2015.

4. McCormack PM, Lawlor R, Donegan C, O'Neill D, Smith S, et al. (1997) Knowledge and attitudes to prescribed drugs in young and elderly patients. Ir Med J 90: 29-30. [Crossref]

5. Ponnusankar S, Surulivelrajan M, Anandamoorthy N, Suresh B (2004) Assessment of impact of medication counselling on patients' medication knowledge and compliance in an outpatient clinic in south India. Patient Educ Couns 54: 55-60. [Crossref]

6. Kerzman H, Epel OB, Toren O (2005) What do discharged patients know about their medication? Patient EducCouns 56: 276-282. [Crossref]

7. Lyons RF, Rumore MM, Merola MR (1996) An analysis of drug information desired by the patient: are patients being told everything they wish to know under OBRA' $90 ?, J$ Clin Pharm Ther 21: 221-228. [Crossref]

8. Bloom M (1992) Patient counseling. American Pharmacy 32:5. 
9. Kessler DA (1991) Communicating with patients about their medications. $N$ Engl $J$ Med 325: 1650- 1652. [Crossref]

10. Perera T, Ranasinghe P, Perera U, Perera S, Adikari M, et al. (2012) Knowledge of prescribed medication information among patients with limited English proficiency in Sri Lanka. BMC Res Notes 5: 658. [Crossref]

11. Ghana Statistical Service, "Population projection by sex, 2010 to 2014, National", Archived from the original on 3 August 2014, Retrieved 3 August 2014.

12. Levi M, Li K, Zhang F (2015) Are women more likely to seek advice than men evidence from the Boardroom. J Risk Financial Manag 8: 127-149. [Crossref]

13. Resnikoff S, Pascolini D, Etya'ale D, Kocur I, Pararajasegaram R (2004) Global data on visual impairment in the year 2002. Bull World Health Organ 82: 844-851. [Crossref]

14. Khandekar R, Mohammed AJ (2009) Gender inequality in vision loss and eye diseases: evidence from the Sultanate of Oman. Indian J Ophthalmol 57: 443-9. [Crossref]

15. Courtright P, Lewallen S (2009) Why are we addressing gender issues in vision loss? Community Eye Health 22: 17-19. [Crossref]

16. Woldeyes A, Adamu Y (2008) Gender differences in adult blindness and low vision, Central Ethiopia. Ethiop Med J 46: 211-218. [Crossref]

17. Ha JF, Longnecker N (2010) Doctor-patient communication: a review. Ochsner $J 10$ : 38-43. [Crossref]

18. Resnikoff S, Felch W, Gauthier TM, Spivey B (2012)The number of ophthalmologists in practice and training worldwide: a growing gap despite more than 200000 practitioners. Br J Ophthalmol 96: 783-7. [Crossref]
19. Boadi-Kusi SB, Ntodie M, Mashige KP, Owusu-Ansah A, AntwiOsei K (2015) A cross-sectional survey of optometrists and optometric practices in Ghana. Clini Exp Optom 98:473-7. [Crossref]

20. Al-Nsour E, Al-Doghim I, Al-Shamaeleh N (2007) Assessment of patient's knowledge on their chronic medications. J Appl Sci 9: 1-6.

21. President's Commission for the Study of Ethical Problems in Medicine and Biomedical and Behavioral Research, Making Health Care Decisions: A Report on the Ethical and Legal Implicaitons of Informed Consent in the Patient-Practitioner Relationship, Washington, DC: US Government Printing Office, October 1982.

22. Ubel PA (1996) Informed consent: from bodily invasion to the seemingly mundane ArchIntern Med156:1262-1263. [Crossref]

23. Paterick TJ, Carson GV, Allen MC, Paterick TE (2008) Medical informed consent: general considerations for physicians. Mayo Clin Proc 83: 313-319. [Crossref]

24. Laine C, Davidoff F (1996) Patient-centered medicine: a professional evolution. JAMA 275: 152-156. [Crossref]

25. Von Korff M, Gruman J, Schaefer J, Curry SJ, Wagner EH (1997) Collaborative management of chronic illness. Ann Intern Med 127: 1097-1102. [Crossref]

26. Woolf SH, Chan EC, Harris R, Sheridan SL, Braddock CH $3^{\text {rd }}$, et al. (2005) Promoting informed choice: transforming health care to dispense knowledge for decision making. Ann Intern Med 143:293-300. [Crossref]

27. Burge S, White D, Bajorek E, Bazaldua O, Trevino J, et al. (2005) Correlates of medication knowledge and adherence: findings from the residency research network of South Texas. Fam Med 37: 712-718. [Crossref]

Copyright: $\mathbb{C} 2015$ Kyei S. This is an open-access article distributed under the terms of the Creative Commons Attribution License, which permits unrestricted use, distribution, and reproduction in any medium, provided the original author and source are credited. 